\title{
Verification of the BOLAM weather prediction model over the area of Cyprus
}

\author{
K. Savvidou ${ }^{1}$, K. Lagouvardos ${ }^{2}$, S. Michaelides ${ }^{1}$, V. Kotroni ${ }^{2}$, and P. Constantinides ${ }^{1}$ \\ ${ }^{1}$ Meteorological Service, Nicosia, Cyprus \\ ${ }^{2}$ National Observatory of Athens, Athens, Greece
}

Received: 24 March 2009 - Revised: 26 August 2010 - Accepted: 10 September 2010 - Published: 4 October 2010

\begin{abstract}
The purpose of this study is the verification of the BOLAM weather prediction model over the area of Cyprus. The verification period spans from 1 January 2007 till 31 December 2007 and the parameters studied are: temperature, wind and precipitation. The model forecasts are compared to the observations recorded at three locations on the island, where Automatic Weather Observing Systems are operated by the Meteorological Service of Cyprus, namely, those of Larnaka and Paphos Airports and at Athalassa. The statistical analysis includes calculation of the mean error, the mean absolute error and the standard deviation. Based on the construction of a contingency table, the probability of detection of a precipitation event and the false alarm rate are calculated. Finally, an example of BOLAM forecasts for a case study of a low pressure affecting Cyprus during winter is presented and discussed.
\end{abstract}

\section{Introduction}

In the framework of the INTERREG RISKMED project (Weather Risk Reduction In The Mediterranean), the Cyprus Meteorological Service implemented the hydrostatic model BOLAM (Bologna Limited Area Model) as the core forecast tool, in order to provide weather risk predictions over the area of Cyprus, including its maritime region. BOLAM weather forecast outputs are used in order to provide warnings for high impact weather (high and low temperatures, strong winds, heavy precipitation, etc.) through a dedicated early warning system. In the framework of this project, oneyear verification of BOLAM forecasts is performed, in order to quantitatively estimate forecast errors. In this manner, the model's forecast skill is tested as a scaled representation of

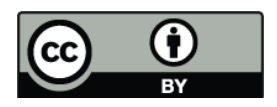

Correspondence to: K. Savvidou (lefele@cytanet.com.cy) the forecast accuracy with reference to observed conditions. The verification is performed using ground weather stations across Cyprus, while a specific case-study with heavy precipitation over the island is investigated in more detail.

The paper is organized as follows: Sect. 2 provides a short description of BOLAM model, as well as a description of the verification method and data used. Section 3 provides verification results for temperature, wind and precipitation; Sect. 4 presents the case-study analysis. Finally, conclusions are drawn in Sect. 5.

\section{BOLAM model, verification data and methodology}

The BOLAM model used in this study is described in Buzzi et al. (1994, 1997, 1998) and Buzzi and Foschini (2000). It is a hydrostatic model on an Arakawa $\mathrm{C}$ grid (rotated lat.-lon. coordinates) and uses $\sigma$ vertical coordinates. BOLAM uses an explicit microphysical scheme with two water and three ice species (Schultz, 1995), as well as the convective parameterization scheme proposed by Kain and Fritsch (1993), with implementation of the modifications suggested by Spencer and Stensrud (1998), regarding the delay of downdrafts in newly developed convection.

For the operational implementation of BOLAM at the Cyprus Meteorological Service, two grids are used:

- The coarse grid consisting of $135 \times 110$ points with a $0.21^{\circ}$ horizontal grid interval $(\sim 23 \mathrm{~km})$, covering the area of the Eastern Mediterranean,

- The fine grid, consisting of $130 \times 140$ points with $0.07^{\circ}$ horizontal grid interval $(\sim 7 \mathrm{~km})$, covering the area of Cyprus and the adjacent seas.

In the vertical, 30 levels are used in the coarse grid and 40 levels in the fine grid, with model top at about $10 \mathrm{hPa}$.

The nesting of the inner grid starts at $t+6$, based on boundary conditions provided by BOLAM outer grid at $2 \mathrm{~h}$ interval.

Published by Copernicus Publications on behalf of the European Geosciences Union. 
The orography fields are derived from a terrain data file with 30 arc s resolution provided by the US Geological Survey (USGS).

The initial and boundary data for BOLAM outer domain are provided by the operational global model GFS, at 6-h intervals. The duration of the simulations is $72 \mathrm{~h}$, initialized every day using the 00:00 UTC GFS data.

The parameters that are verified are the temperature, wind speed and precipitation. The observations are provided by three automatic weather observing stations located at the Airports of Larnaka $\left(33.37^{\circ} \mathrm{E}, 34.52^{\circ} \mathrm{N}\right)$ and Paphos $\left(32.49^{\circ} \mathrm{E}, 34.72^{\circ} \mathrm{N}\right)$ which are coastal stations, and at Athalassa $\left(33.4^{\circ} \mathrm{E}, 35.1^{\circ} \mathrm{N}\right)$, which is an inland station with elevation $162 \mathrm{~m}$ a.m.s.l. (above mean sea level). For the temperature and the wind speed, the observed values were compared against the fine grid forecast values at 11 lead times: $T+12$, $\mathrm{T}+18, \mathrm{~T}+24, \ldots, \mathrm{T}+72$, for the entire 2007. The forecast values are selected from the nearest to the stations land grid box of the model. The Mean Error (ME), the Mean Absolute Error (MAE) and their respective standard deviations were calculated for the whole year, but also separately for the cold and warm months of the year. For the precipitation, the comparison was performed through the use of the daily recorded precipitation amounts at the three stations and of BOLAM fine grid forecasts, averaged over the 5 grid boxes in cross arrangement around each station. The "probability of detection' (POD) and the "false alarm rate" (FAR) for four precipitation thresholds: 1, 5, 10 and $20 \mathrm{~mm}$ for 2007 were calculated.

\section{Results}

\subsection{Wind speed}

The forecast skill of the model for the wind is good (see Fig. 1a) and especially for Athalassa, where ME is less than $1 \mathrm{kt}$ for all the lead times $(1 \mathrm{kt}=0.514 \mathrm{~m} / \mathrm{s})$. At Paphos and Larnaka, the model underestimates the wind speed at all lead times with ME exhibiting a diurnal cycle. The highest underestimation is found at lead times which correspond at 12:00 UTC; less than $2 \mathrm{kt}$ for Paphos and around $3 \mathrm{kt}$ for Larnaka. The seasonal verification (Fig. $1 \mathrm{~b}$ and c) of the model reveals that at Athalassa the wind speed is overestimated during the cold months (with ME values lower than $1 \mathrm{kt}$ ) and is underestimated during the warm months (when the ME reaches its maximum values, around $2.5 \mathrm{kt}$ ) at lead times which correspond at 18:00 UTC. The seasonal pattern of ME at Larnaka reveals that the maximum values are noted again at lead times which correspond to local noon and the values are higher during the warm months, around $4 \mathrm{kt}$. This can be attributed to the weakness of the model to predict the diurnal cycle of the sea breeze. Similar results concerning the magnitude of wind forecast errors were also found by
Wind Speed Mean Error

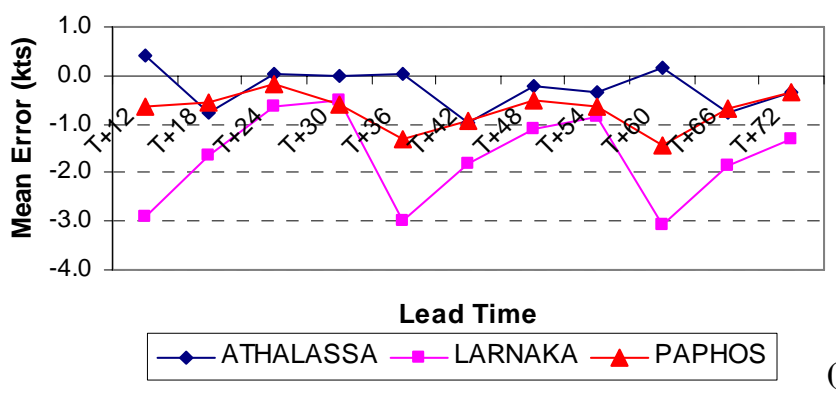

(a)

Wind Speed ME for cold months

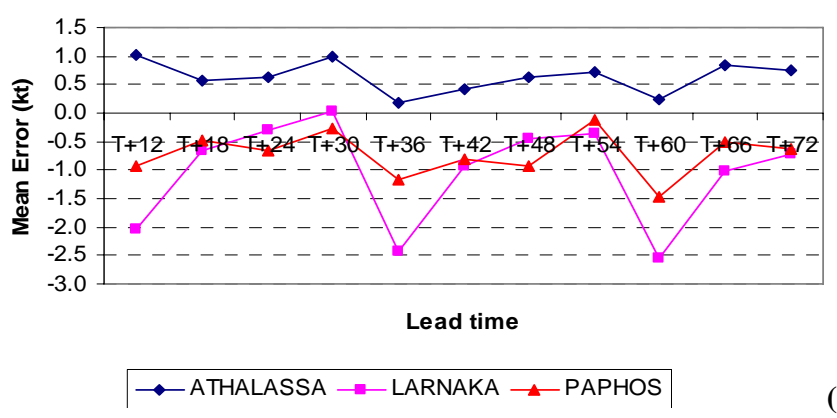

(b)

Wind Speed ME for warm months

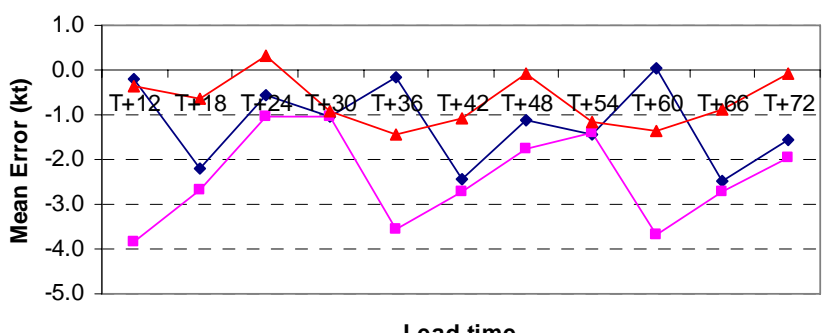

- ATHALASSA $\rightarrow$ LARNAKA $\leadsto$ PAPHOS

(c)

Fig. 1. Wind verification: (a) mean error for the year, (b) mean error for the cold months, and (c) mean error for the warm months.

Lagouvardos et al. (2003) for the verification of BOLAM model over Greece.

The MAE and the Standard Deviation (STDEV) of the ME have a similar behavior in all three stations and for all lead times (see Fig. 2a and b). The lowest values are found at Athalassa and the highest at Larnaka. Furthermore, it should be noted that the forecast skill does not decrease with forecast lead time within the $72 \mathrm{~h}$ of the simulation period.

\subsection{Temperature}

The temperature is underestimated by the model in all three stations and at all lead times (Fig. 3a). A 24-h cyclic behavior is noted for forecast lead times of the second and third day 
Wind Speed Mean Absolute Error

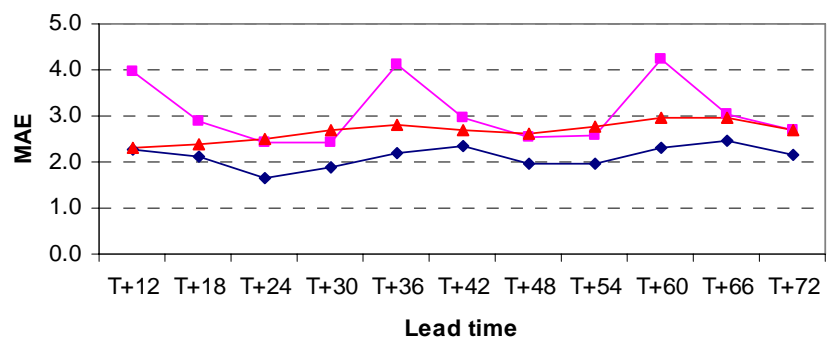

$\bullet$ ATHALASSA $\multimap$ LARNAKA $\longleftarrow$ PAPHOS

Wind Speed STDEV of ME

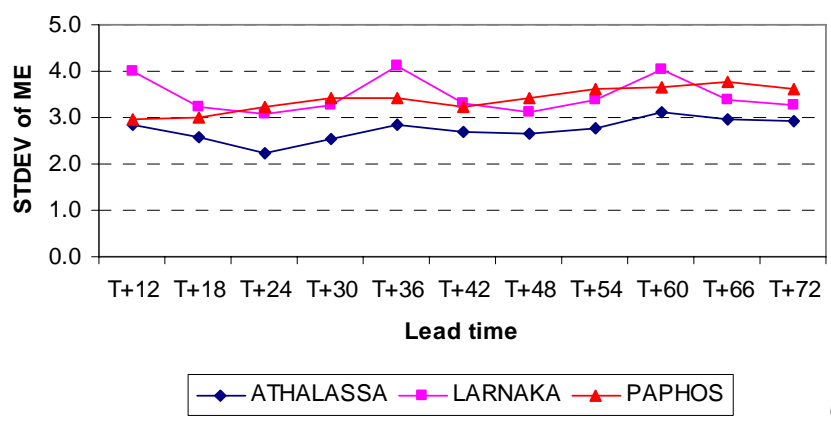

Fig. 2. Wind verification: (a) mean absolute error, and (b) standard deviation of the mean error.

of the simulation period. For the first 3 lead times, the ME is less than or equal to $1 \mathrm{~K}$. The best forecast skill is found at Athalassa and the worst at Paphos. The highest absolute values of the ME are found at lead times which correspond at 06:00 UTC and the lowest absolute values are found during nighttime (18:00 and 00:00 UTC). The seasonal verification reveals (see Fig. $3 \mathrm{~b}$ and c) that during the cold months, the temperature at Athalassa and Larnaka is overestimated during night and underestimated during day. The largest underestimation is found during the warm months at Larnaka $(4-5 \mathrm{~K})$ at lead times which correspond again at 06:00 UTC.

The temperature MAE (Fig. 4a) has a periodical behavior with peaks at 06:00 UTC and low points at 18:00 UTC. The highest values are found at coastal stations. The STDEV of ME (Fig. 4b) follows a similar behavior, but the lowest values for the coastal stations are found at 00:00 UTC. Once more, the verification has shown that the forecast skill does not decrease within the 72-h duration of the simulation.

The underestimation of the temperature by the model can be attributed to the weakness of the model to predict the daily superadiabatic warming especially during summer and the radiation cooling during winter, since the model produces forecasts for the temperature at $2 \mathrm{~m}$. Also, the largest underestimation which is noted at 06:00 UTC can be associated with the time lag of the model in predicting the transition
Temperature Mean Error

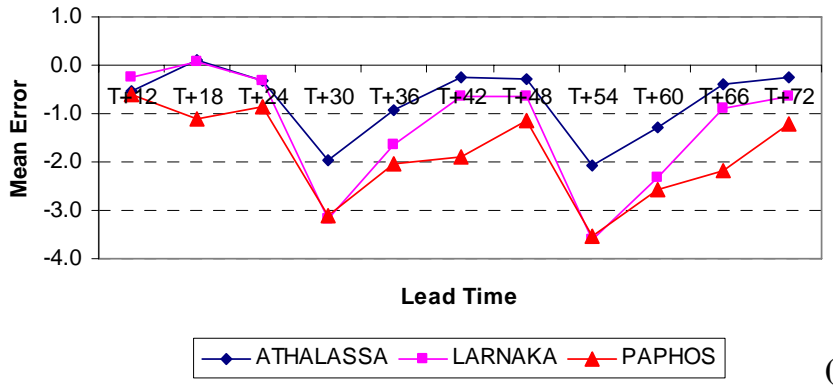

(a)

Temperature Mean Error for Cold months

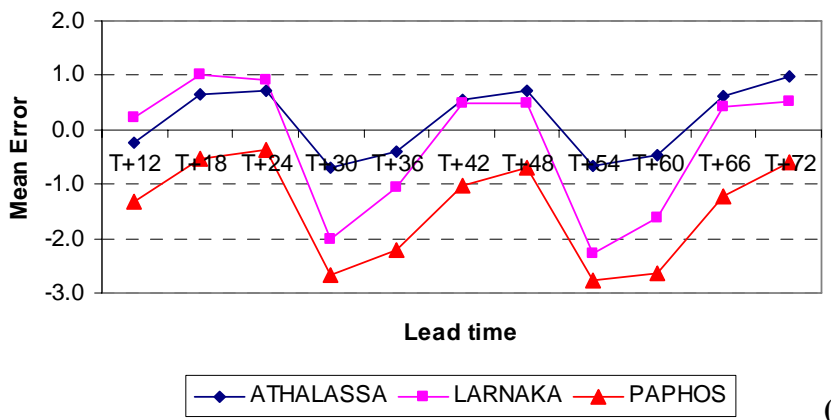

(b)

Temperature Mean Error for Warm months

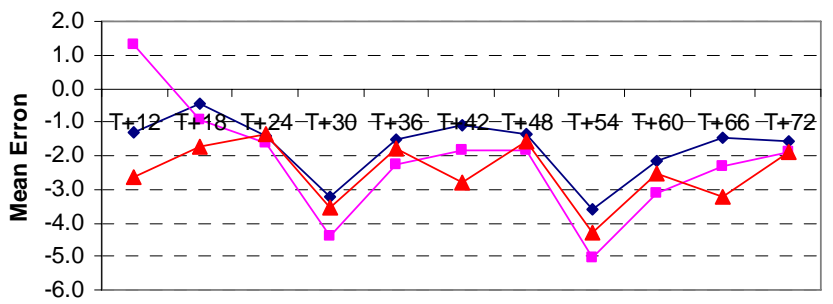

Lead time

- ATHALASSA —LARNAKA —-PAPHOS

(c)

Fig. 3. Temperature verification: (a) mean error for the year, (b) mean error for the cold months, and (c) mean error for the warm months.

time between the nocturnal katabatic wind to the daily prevailing wind, but this must be examined in a future study.

\subsection{Precipitation}

The results of the calculations of POD and FAR for the four precipitation thresholds are shown in Table 1 . As it was expected, as the precipitation threshold increases, the POD decreases, except at Larnaka where, an increase in POD is noted from $5 \mathrm{~mm}$ to $10 \mathrm{~mm}$. At Larnaka, the POD is higher than the other two stations for almost all the precipitation thresholds. The lowest FAR is found at Athalassa (13\% 
Table 1. POD and FAR for the three stations and for the four precipitation thresholds.

\begin{tabular}{|c|c|c|c|c|c|c|}
\hline \multirow{2}{*}{$\begin{array}{l}\text { Precipitation } \\
\text { Thresholds } \\
(\mathrm{mm})\end{array}$} & \multicolumn{2}{|c|}{ Athalassa } & \multicolumn{2}{|c|}{ Larnaka } & \multicolumn{2}{|c|}{ Paphos } \\
\hline & $\begin{array}{c}\text { POD } \\
(\%)\end{array}$ & $\begin{array}{c}\text { FAR } \\
(\%)\end{array}$ & $\begin{array}{c}\text { POD } \\
(\%)\end{array}$ & $\begin{array}{c}\text { FAR } \\
(\%)\end{array}$ & $\begin{array}{c}\text { POD } \\
(\%)\end{array}$ & $\begin{array}{c}\text { FAR } \\
(\%)\end{array}$ \\
\hline 1 & 88 & 48 & 96 & 43 & 91 & 33 \\
\hline 5 & 67 & 50 & 80 & 48 & 81 & 19 \\
\hline 10 & 64 & 13 & 89 & 38 & 56 & 31 \\
\hline 20 & 40 & 33 & 60 & 40 & 50 & 80 \\
\hline
\end{tabular}

Temperature MAE

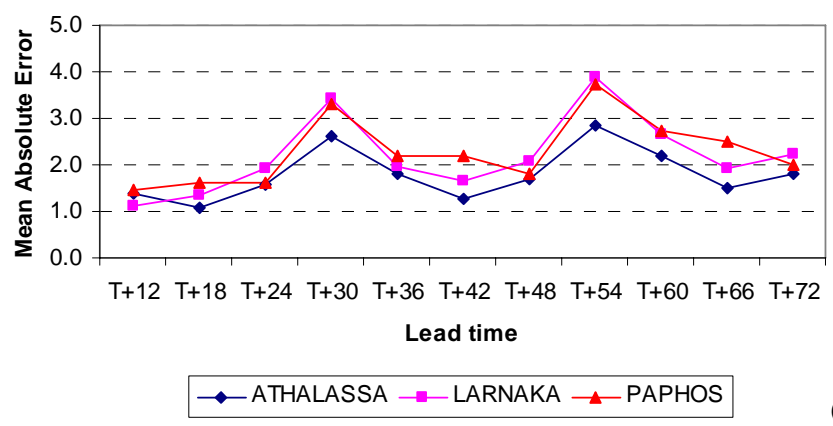

Temperature STDEV of ME

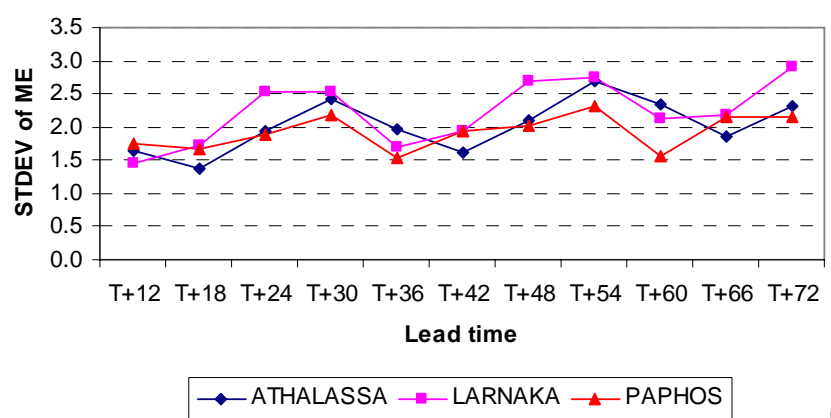

Fig. 4. Temperature verification: (a) MAE, and (b) STDEV of ME.

for the $10 \mathrm{~mm}$ threshold) and at Paphos (19\% for the $5 \mathrm{~mm}$ threshold).

It is also interesting to present the results of the ME and MAE for the hit events (forecast and observed) which are shown in Table 2.

The values of the ME and MAE are similar in all three stations, indicating that there is not an area-dependent bias of the model in forecasting precipitation over the domain of simulation.
Table 2. The ME and MAE for the hit events.

\begin{tabular}{lccc}
\hline & Athalassa & Larnaka & Paphos \\
\hline ME & 1.1 & 1.2 & 0.8 \\
MAE & 4.3 & 3.9 & 4.1 \\
\hline
\end{tabular}

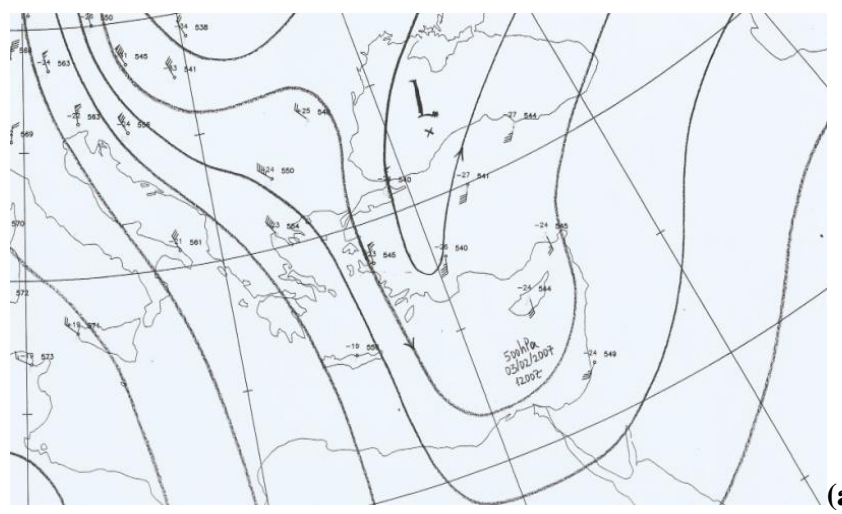

(a)

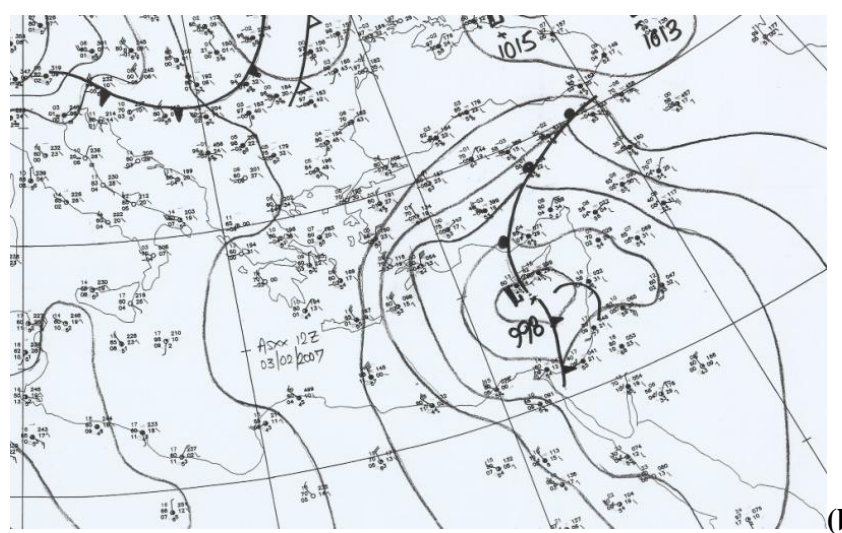

(b)

Fig. 5. (a) $500 \mathrm{hPa}$ geopotential height analysis at 12:00 UTC, 3 February 2007. (b) Mean sea level pressure analysis at 12:00 UTC, 3 February 2007.

(b)

\section{A case-study: a depression that affected Cyprus on 3 February 2007}

On 3 February 2007, a diffluent upper- level trough associated with a deep surface low $(998 \mathrm{hPa})$ centered south of Cyprus (see Fig. 5a and b) affected the area. In $12 \mathrm{~h}$, it moved to the east, leaving the area in a northwest flow (not shown). This well organized frontal depression resulted in high accumulation precipitation amounts, as shown in Fig. 6 (there is no accessibility to measurements in the north part of the island). In the southeast part of the island, the daily recorded precipitation reached $160 \mathrm{~mm}$. At Larnaka, the recorded precipitation between 15:00 and 18:00 UTC was $35.2 \mathrm{~mm}$. In order to evaluate the model's skill in predicting the depressions that affected the area of Cyprus, a first comparison is performed between the actual surface charts and the $500 \mathrm{hPa}$ isobaric surface with the model's forecasts. 


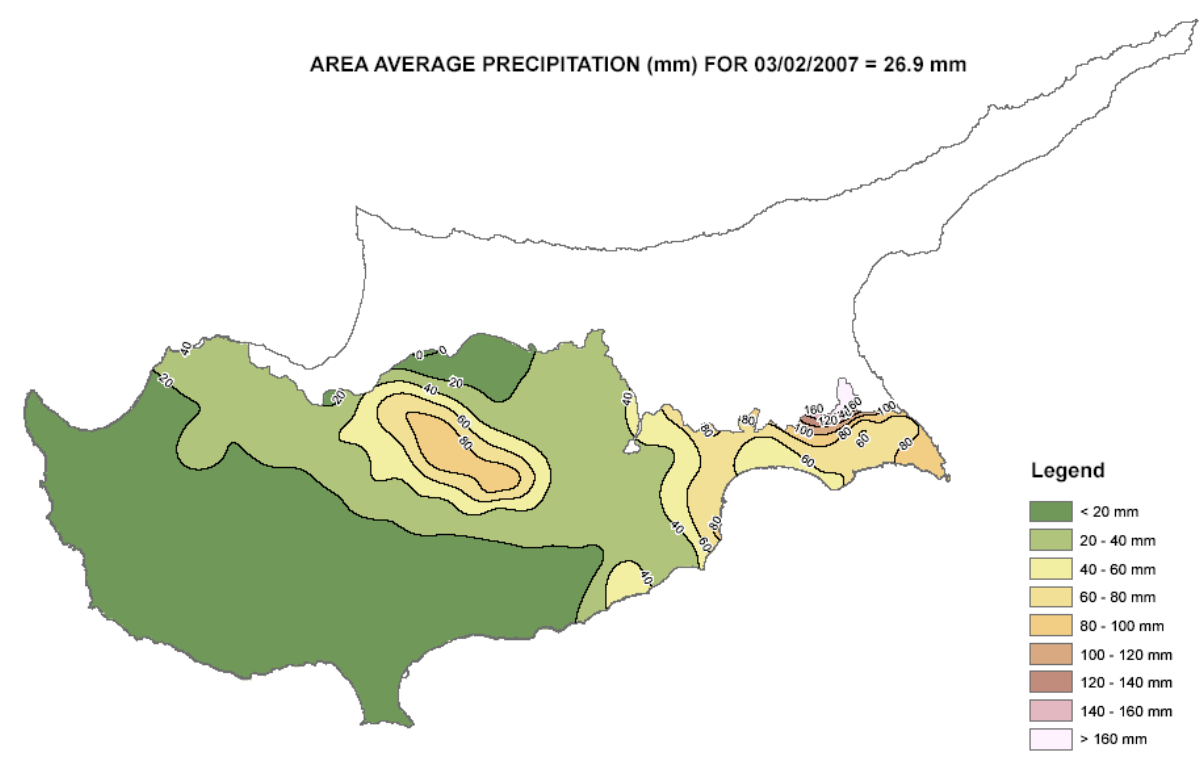

Fig. 6. The area averaged precipitation for 3 February 2007.

The BOLAM coarse grid forecasts are shown in Fig. 7. The $\mathrm{T}+60$ forecast of the $500 \mathrm{hPa}$ geopotential height (Fig. 7a) and of mean sea level pressure (Fig. 7b), valid at 12:00 UTC, 3 February 2007, show the trough positioned more to the east, with respect to the verifying analysis (shown in Fig. 5a), while the surface low is predicted over the northeastern part of the island, with a central pressure of $\sim 1002 \mathrm{hPa}, 4 \mathrm{hPa}$ shallower than the real conditions (shown in Fig. 5b). The $\mathrm{T}+36$ forecasts of the same fields (shown in Fig. $7 \mathrm{c}$ and d), depict a small scale cut-of low at the $500 \mathrm{hPa}$ level which is not evident in the analysis chart, while the low pressure at the surface is to the west with respect to its real position, but once more about $2 \mathrm{hPa}$ shallower than the actual low. Finally, the $\mathrm{T}+12$ forecast (Fig. 7e and f) reproduces well the structure at the $500 \mathrm{hPa}$ level, and the forecast surface low is very close to the actual one. It can be stated here that the model was able to catch the evolution of the surface and upper air patterns, two days before the synoptic event.

Accumulated precipitation maps, provided by BOLAM fine grid, are shown in Fig. 8 (first day of simulation). An examination of the maps shows good results as far as the location of the precipitation is concerned, with precipitation amounts exceeding $40 \mathrm{~mm}$ within $3 \mathrm{~h}$ over southern Cyprus between 09:00 and 12:00 UTC (Fig. 8a) and later over the central part of the island. The results for the third day of simulation were quite satisfactory, as it concerns the location of precipitation but the predicted amount was very low; $15 \mathrm{~mm}$ within $3 \mathrm{~h}$. For the second day of simulation, the forecast output was totally wrong; precipitation was predicted only over the northernmost part of the island.

\section{Conclusions}

Verification of model outputs is an important component in weather forecasting, as it is through this phase that the confidence to an operational model is built. The Cyprus Meteorological Service verifies the limited area models that it runs operationally (see Orphanou et al., 2006); this is the first time that the BOLAM model is verified over the area of Cyprus. In this study, one year of BOLAM model forecasts over the area of Cyprus are verified by comparing the model output with the observations at three main locations over the island. The verified parameters are temperature, wind speed and precipitation. The verification was performed using data for the year 2007.

Verification of the wind speed has shown that the best performance is found at Athalassa, the inland station, with ME less than $1 \mathrm{kt}$. The seasonal verification reveals higher ME during the warm months, around $2.5 \mathrm{kt}$ at lead times which correspond at 18:00 UTC. Over the coastal stations, the wind speed is underestimated, with the highest ME around $4 \mathrm{kt}$ at Larnaka during the warm months and at 12:00 UTC. Overall, the skill of the model forecasts of the wind speed is very good.

The temperature is generally underestimated by the model except during nighttime and during the cold months at Athalassa and Larnaka. The absolute values of ME are higher during the warm months and during daytime. The highest absolute values are found at 06:00 UTC at Larnaka, being around $4-5 \mathrm{~K}$. The highest absolute values during the cold months are noted at 06:00 UTC at Paphos, being around $3 \mathrm{~K}$.

The forecast skill of the model in predicting precipitation is better at Larnaka for all the precipitation thresholds, as the values of POD are higher than the values for the other two 


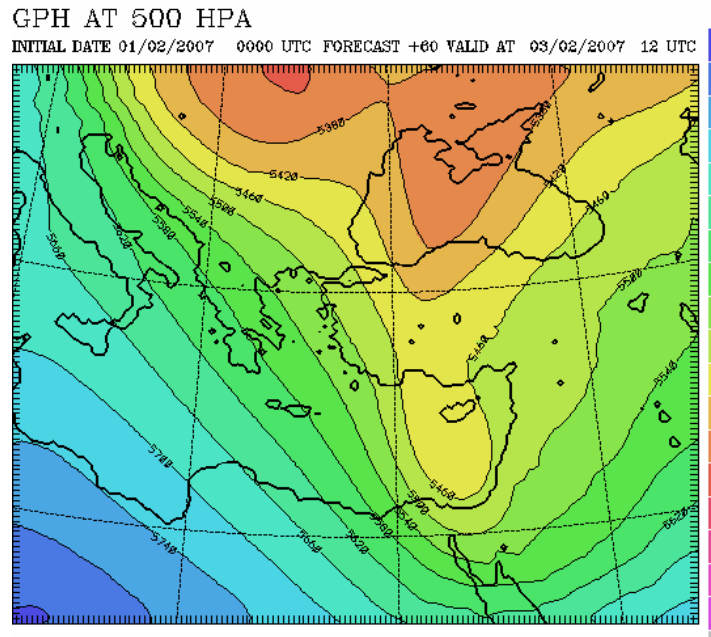

CYPRUS METEOROLOGICAL IERTICE

GPH AT 500 HPA

INTTAL DATE 03/03/2007 0000 UTC FORECAST + 3 VALD AT OS/03/3007 12 UTC

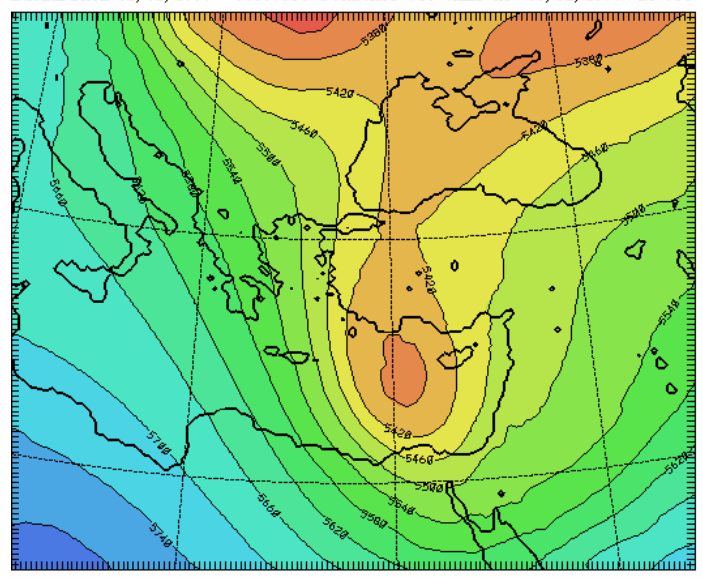

CYPRUS HETEOROLOGICAL TERTICE

GPH AT 500 HPA

INTTAL DATE 03/02/2007 0000 UTC FORECAST +12 VALID AT 03/02/2007 12 UTC

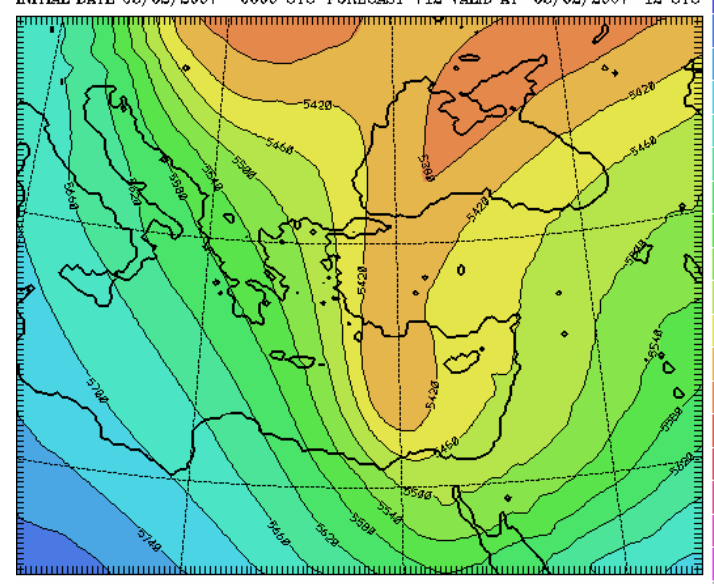

CYPRUS METEOROLOGICAL SERTICE
M.S.L. PRESSURE (HPA)

INTTAL DATE 01/02/2007 0000 UTC FORECAST + 60 VALID AT $03 / 02 / 2007 \quad 12$ UTC

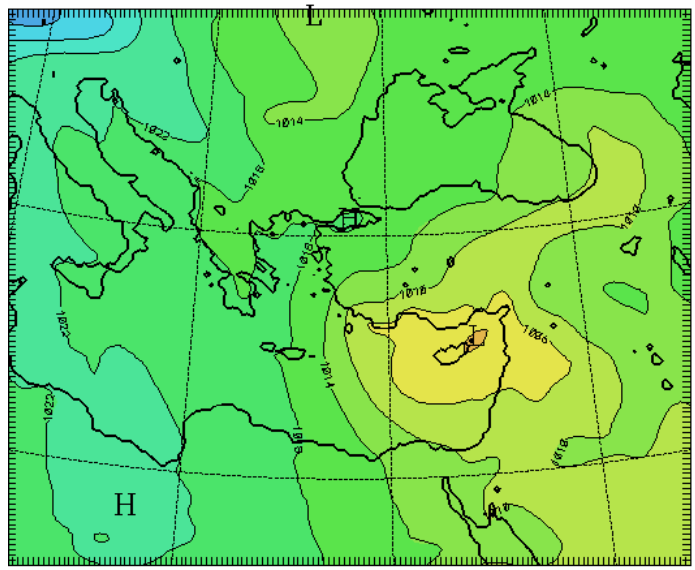

CYPRUS METEOROLOGCAL SERTCE

a)

M.S.L. PRESSURE (HPA)

INTTAL DATE 02/02/2007 0000 UTC FORECAST + SE VALID AT OS/02/2007 12 UTC
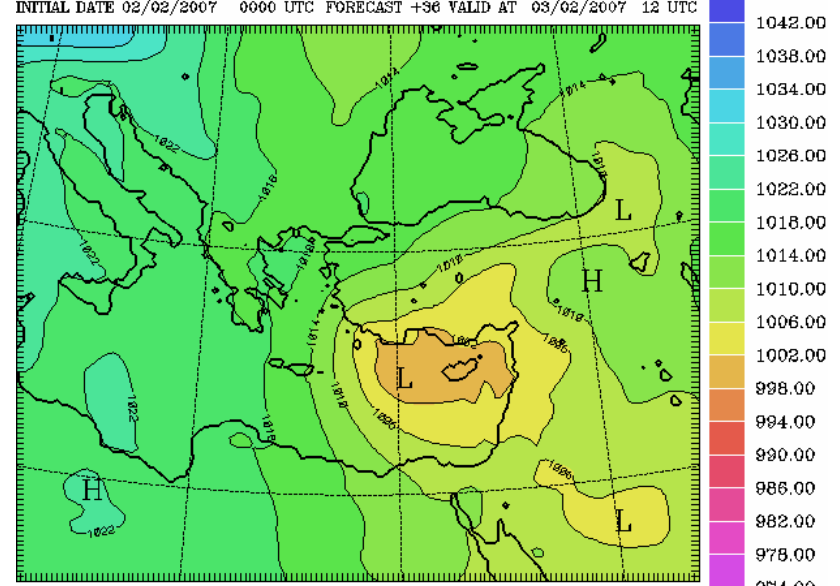

CYPRUS METEOROLOGICAL IERTICE

c)

M.S.L. PRESSURE (HPA)

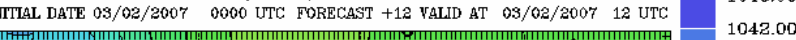
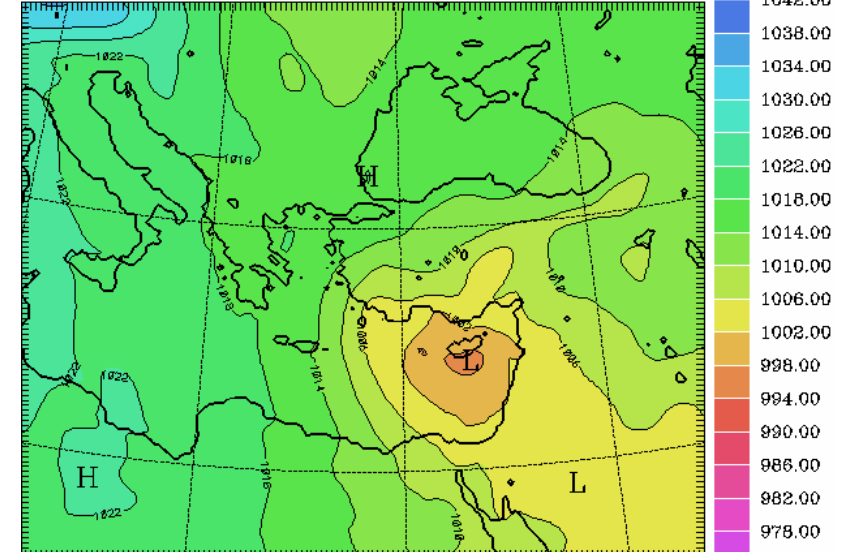

CYPRUS METEOROLOGICAL SERTICE

(e)

Fig. 7. (a) $\mathrm{T}+60500 \mathrm{hPa}$ geopotential height, verifying at 12:00 UTC, 3 February 2007. (b) $\mathrm{T}+60$ mean sea level pressure, verifying at 12:00 UTC, 3 February 2007. (c) $\mathrm{T}+36500 \mathrm{hPa}$ geopotential height, verifying at 12:00 UTC, 3 February 2007 . (d) $\mathrm{T}+36 \mathrm{mean}$ sea level pressure, verifying at 12:00 UTC, 3 February 2007. (e) T+12 500 hPa geopotential height, verifying at 12:00 UTC, 3 February 2007. (f) T+12 mean sea level pressure, verifying at 12:00 UT, 3 February 2007. 


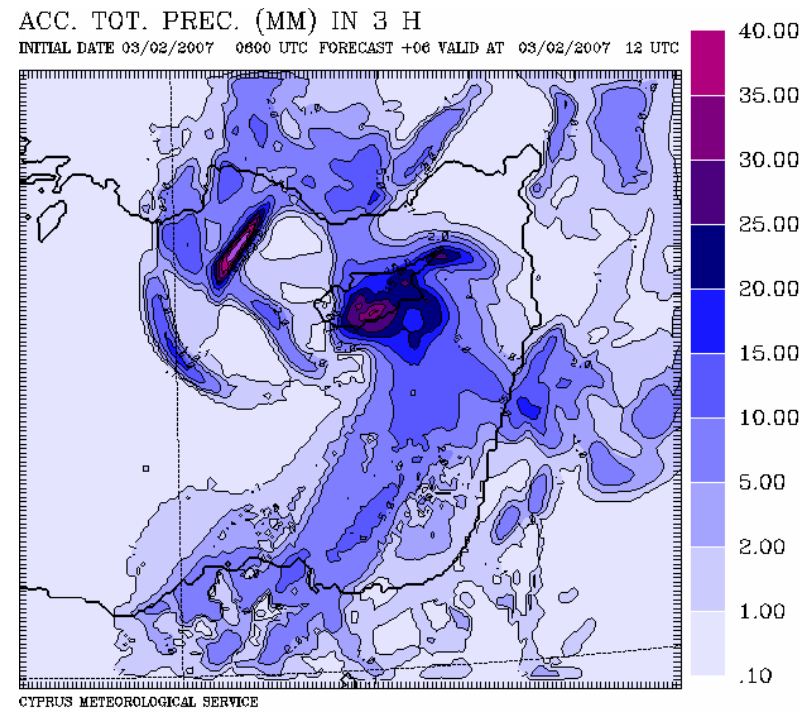

ACC. TOT. PREC. (MM) IN $3 \mathrm{H}$

INTTAL DATE 03/02/2007 0800 UTC FORECAST +09 YALLD AT 03/02/2007 15 UTC 40.00

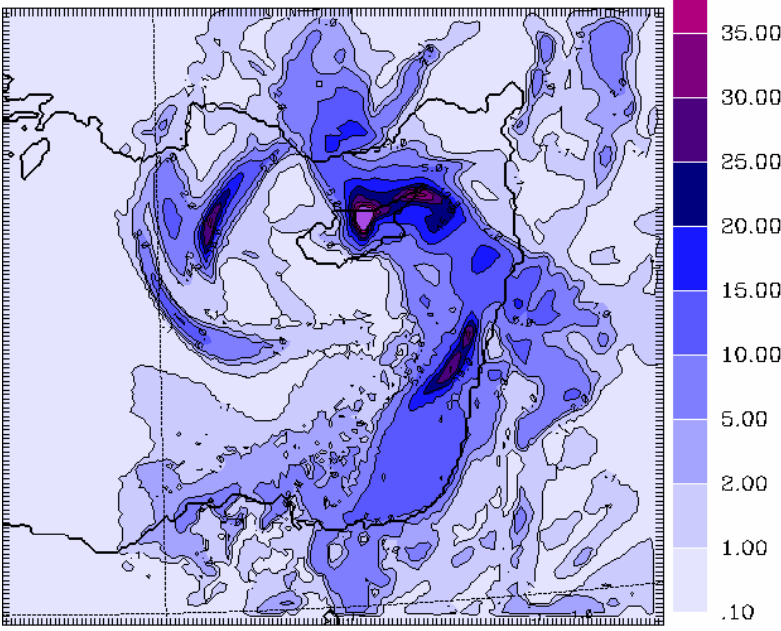

(a)

ACC. TOT. PREC. (MM) IN $3 \mathrm{H}$

INTIAL DATE 0S/02/2007 0800 UTC FORECAST +12 VALLD AT OS/03/2007 10 U U

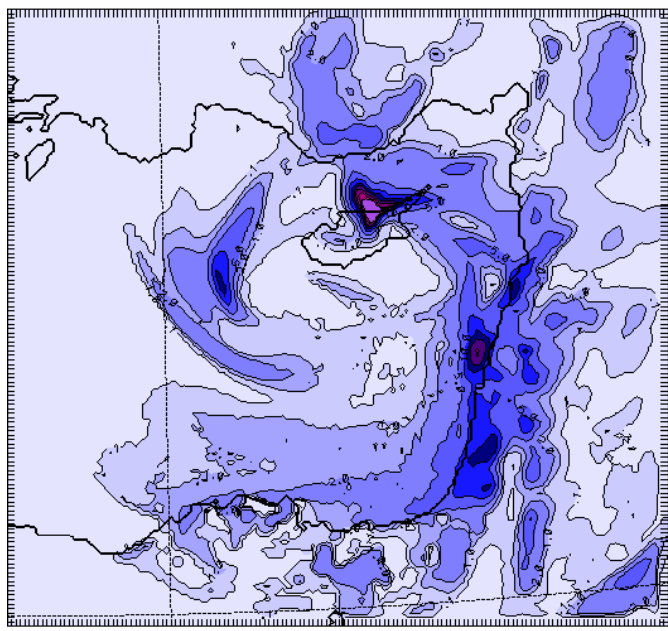

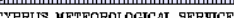

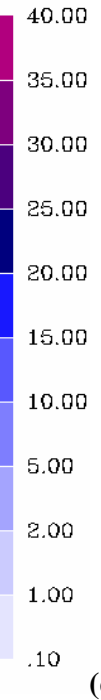

ACC. TOT. PREC. (MM) IN $3 \mathrm{H}$

INTTAL DATE 03/02/2007 0B00 UTC FORECAST +15 VALD AT 03/02/2007 21 UTC

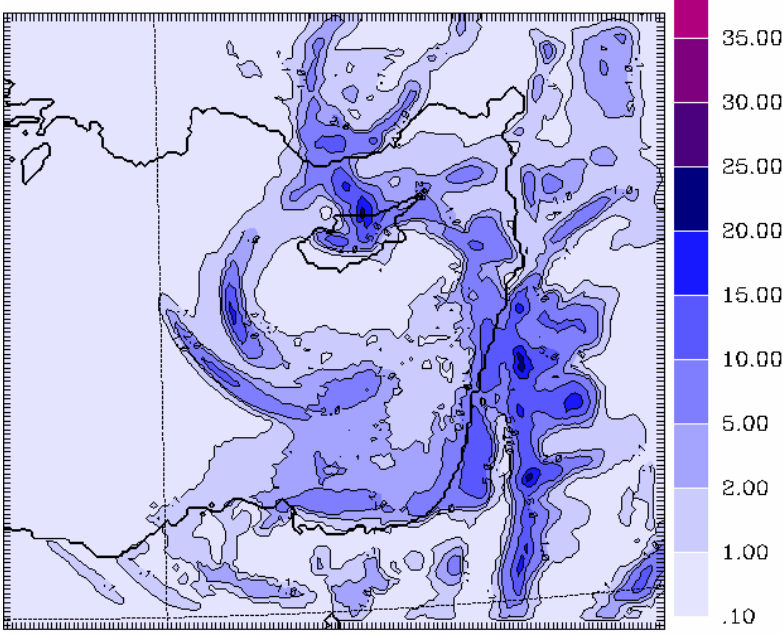

(c)

Fig. 8. (a) 3-h accumulated precipitation, ending at 12:00 UTC, 3 February 2007. (b) 3-h accumulated precipitation, ending at 15:00 UTC, 3 February 2007. (c) 3-h accumulated precipitation, ending at 18:00 UTC, 3 February 2007. (d) 3-h accumulated precipitation, ending at 21:00 UTC, 3 February 2007.

stations. Meanwhile, the values of FAR for the two higher precipitation thresholds are lower at Athalassa than at the other two stations. Finally, the analysis of a specific case study, showed the ability of the model to provide accurate forecasts for events producing high-impact weather. It is in the authors' plans to continue the verification of the model for a longer period and to extend the verification to the warnings provided by BOLAM.

Acknowledgements. This work was carried out as part of the RISKMED project which was co-funded by the European Union (INTERREG IIIB) and the Government of Cyprus. The authors acknowledge the provision of BOLAM model by Andrea Buzzi
(ISAC-CNR, Italy) and his help during the implementation of the model at the Cyprus Meteorological Service. The authors are also grateful to the National Centers for Environmental Prediction (USA) for providing GFS initial and forecast field data which allow the operational use of meteorological models at the Cyprus Meteorological Service.

Edited by: K. Nicolaides and A. Orphanou Reviewed by: S. Davolio and F. Tymvios 


\section{References}

Buzzi, A., Fantini, M., Malguzzi, P., and Nerozzi, F.: Validation of a limited area model in cases of Mediterranean cyclogenesis: surface fields and precipitation scores, Meteorol. Atmos. Phys., 53, 137-153, 1994.

Buzzi, A., Cadelli, R., and Malguzzi, P.: Low level jet simulation over the Antarctic ocean, Tellus A, 49, 263-276, 1997.

Buzzi, A., Tartaglione, N., and Malguzzi, P.: Numerical simulations of the 1994 Piedmont flood: role of orography and moist processes, Mon. Weather Rev., 126, 2369-2383, 1998.

Buzzi, A. and Foschini, L.: Mesoscale meteorological features associated with heavy precipitation in the southern Alpine region, Meteorol. Atmos. Phys., 72, 131-146, 2000.

Kain, J. S. and Fritsch, J. M.: Convective parameterization for mesoscale models: The Kain-Fritsch scheme, The Representation of Cumulus in numerical models, Meteor. Monogr., No 46, Am. Meteororl. Soc., 165-177, 1993.
Lagouvardos, K., Kotroni, V., Koussis, A., Feidas, C., Buzzi, A., and Malguzzi, P.: The meteorological model BOLAM at the National Observatory of Athens: assessment of two-year operational use, J. Appl. Meteorol., 42, 1667-1678, 2003.

Orphanou, A., Michaelides, S., Savvidou, K., Constantinides, P., Schulz, J.-P., and Voigt, U.: Preliminary verification results of the DWD limited area model LME and evaluation of its storm forecast skill over the area of Cyprus, Adv. Geosci., 7, 169-174, 2006, http://www.adv-geosci.net/7/169/2006/.

Schultz, P.: An explicit cloud physics parameterization for operational numerical weather prediction, Mon. Weather Rev., 123, 3331-3343, 1995.

Spencer, P. L. and Stensrud, D. J.: Flash flood events: importance of the subgrid representation of convection, Mon. Weather Rev., 126, 2884-2912, 1998. 